\title{
Electrochemical Detector Using Carbon Fiber Working Electrode for Micro High Performance Liquid Chromatography
}

\author{
Masashi Goto, ${ }^{*}$ Ken ShImada**, Toyohide TAKEUCHI** and Daido IshiI** \\ * Research Center for Resource and Energy Conservation, Nagoya University, Nagoya 464 \\ **Department of Applied Chemistry, Faculty of Engineering, Nagoya University, Nagoya 464
}

\begin{abstract}
A tubular electrolytic cell of ultra micro volume, made of a single carbon fiber $(7 \mu \mathrm{m}$ o.d., $15 \mathrm{~mm}$ length) as the working electrode material and a fused silica tube $(50 \mu \mathrm{m}$ i.d.) as the flow cell part, was designed for use as the electrochemical detector in micro high performance liquid chromatography (micro HPLC). The effective cell volume is about $0.03 \mu \mathrm{l}$. This detector with carbon fiber was useful for detection of catecholamines and their metabolites. Their detection limits were about $1-2 \mathrm{pg}$ and the linear dynamic range was about $10^{3}$. The detector was successfully applied to urinary catecholamine analysis by micro HPLC and to rapid detection of electroactive species in fast micro HPLC.
\end{abstract}

Keywords Electrochemical detector, micro electrode, micro high performance liquid chromatography, catecholamine related compounds, carbon fiber

High performance liquid chromatography using micro columns of bore sizes less than $0.5 \mathrm{~mm}$ inner diameter, "micro HPLC", has the advantages of reducing the quantity of sample, mobile phase and packing material. ${ }^{1}$ So it results in increasing mass sensitivity and reducing costs. For those reasons, micro HPLC is very suitable for the analyses of small samples such as human body fluids.

According to this miniaturization of HPLC apparatus, it is necessary to minimize the cell volume of the detector. Since electrochemical processes take place at the electrode surface rather than in solution, electrochemical detectors have a real advantage for detection in micro HPLC. ${ }^{2-6}$ Carbon fiber, which is known as a material of micro electrode for in vivo voltammetry, seems to be very useful for that purpose, because of its very small diameter: $7-10 \mu \mathrm{m} .^{7-13}$ Jorgenson $e$ al. first constructed on-column electrochemical detector with a single graphite fiber electrode for open-tubular liquid chromatography. ${ }^{14-16}$ However, a precision positioner and a hundred-time microscope are required in construction of their detector assembly. In this work, a simple electrolytic cell of ultra micro volume in tubular type for electrochemical detector was constructed without such sophisticated instruments for micro HPLC and its performance was tested for the detection of catecholamines and their metabolites.

\section{Experimental}

\section{Apparatus}

The block diagram of basic chromatographic

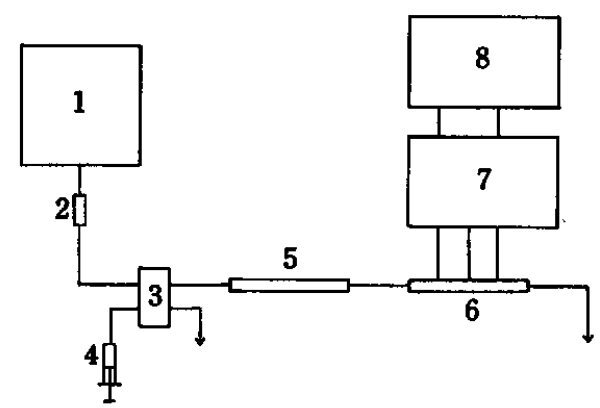

Fig. I Block diagram of micro high performance liquid chromatograph with electrochemical detector. 1=Pump, $2=$ damper, $3=$ sample injector $(0.02 \mu \mathrm{l}), 4=$ micro syringe, $5=$ micro separation column, $6=$ micro electrolytic cell, $7=$ voltammetric instrument, $8=$ recorder.

apparatus is shown in Fig. 1. In the basic experiment, a pump (NP-DX1, Nihonseimitu Co.), voltammetric detector (VMD-101, YANACO), micro valve injector (20 nl, ML-422, JASCO), recorder (3056, YEW) were employed. In the application experiment, micro Metric metaling pump (LDC, Milton Roy Co.) for fast micro HPLC or micro feeder (MF2, Azuma Denki Co.) for the other were employed as the pumps. The micro separation column was filled with ODS-Hypersil (3 $\mu \mathrm{m})$ in a fused silica tube $(50 \times 0.35 \mathrm{~mm}$ i. d.).

\section{Construction of electrochemical detector cell}

The fundamental construction of detector cell is shown in Fig. 2. A single carbon fiber (M40, 


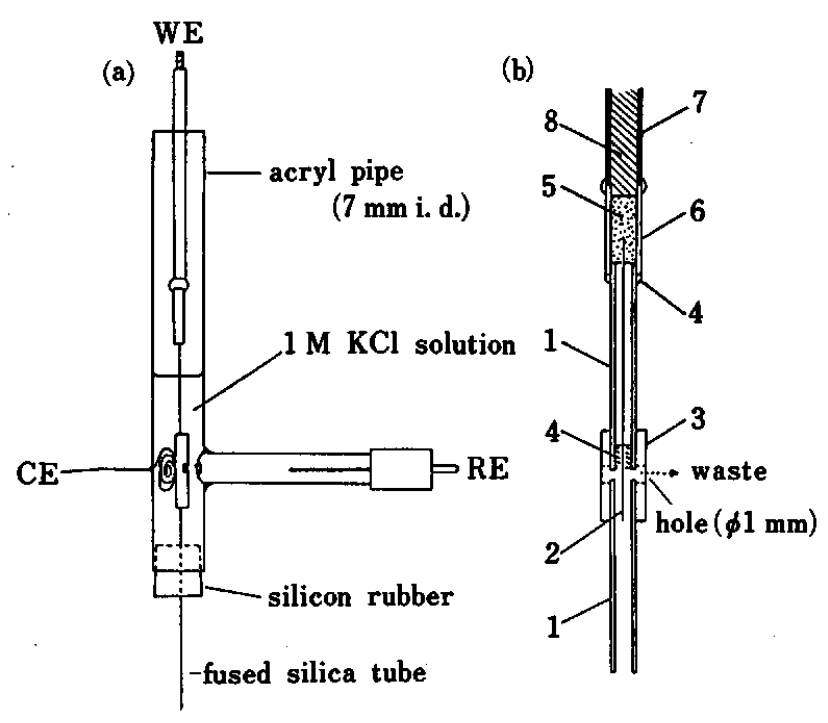

Fig. 2 Electrolytic cell structure of the tubular type with a single carbon fiber working electrode. (a) Whole cell, (b) detail of working electrode. 1=Fused-silica tube (50 $\mu \mathrm{m}$ i.d.), $2=$ carbon fiber ( $7 \mu \mathrm{m}$ diameter), $3=$ teflon tube, 4=adhesive resin, $5=$ carbon paste, $6=$ glass tube, $7=$ insulator, $8=$ electric wire.

TOREKA) of $7 \mu \mathrm{m}$ diameter and $15 \mathrm{~mm}$ length was inserted into the fused silica tube $(50 \mu \mathrm{m}$ i.d.) to serve as the working electrode. A silver-silver chloride reference electrode and a platinum counter electrode were placed outside of the tube near the outlet of solution. The effective cell volume was about $0.03 \mu \mathrm{l}$. The carbon fiber working electrode was electrochemically pretreated according to the following procedure before use. 8,10 An anodic potential of triangular form (initial potential $0 \mathrm{~V}$, amplitude $2.9 \mathrm{~V}$, frequency 70 $\mathrm{Hz}$ ) was applied for $20 \mathrm{~s}$ in $0.002 \mathrm{M} \mathrm{H}_{2} \mathrm{SO}_{4}$.

\section{Chemicals}

A standard solution of catecholamines containing dopamine (DA), adrenaline (AD), noradrenaline (NA) and 3,4-dihydroxyphenylalanine (DOPA) (each 1 $\mathrm{mg} / \mathrm{ml}$ ), and a standard solution containing 3,4dihydroxyphenyl glycol, NA, AD, 3,4-dihydroxybenzylamine (DHBA), normethanephrine (NM), 3,4-dihydroxyphenylacetic acid (DOPAC) and DA (each 1 $\mathrm{mg} / \mathrm{ml}$ ) were prepared as the stock solutions and used after dilution with Britton-Robinson A buffer solution $\left(\mathrm{H}_{3} \mathrm{PO}_{4}, 2.71 \mathrm{ml} / \mathrm{l} ; \mathrm{CH}_{3} \mathrm{COOH}, 2.36 \mathrm{ml} / \mathrm{l}\right.$; boric acid, $2.47 \mathrm{~g} / \mathrm{l} ; \mathrm{pH}$ 1.8). The mobile phases used were mixtures of methanol and potassium phosphate buffer containing sodium octylsulfate and $0.2 \mathrm{mM}$ EDTA. The details of the mobile phase composition are shown in the footnote in each figure. All chemicals were obtained through Rikaken Co. or Katayama Chemical Co., Nagoya, Japan.

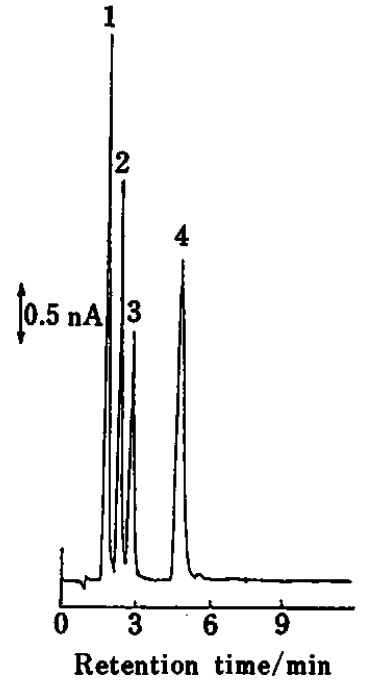

Fig. 3 Typical chromatogram of a standard mixture of catecholamines with carbon fiber working electrode electrochemical detector. Peaks: $1=\mathrm{NA}, 2=\mathrm{AD}, 3=\mathrm{DOPA}$, 4=DA. Sample amounts injected: $100 \mathrm{pg}$ each. Mobile phase: methanol-potassium phosphate buffer $(\mathrm{pH} 3.0)=$ $1 / 9$ containing $0.4 \mathrm{mM}$ sodium octylsulfate and $0.2 \mathrm{mM}$ EDTA. Flow rate: $4.8 \mu \mathrm{l} / \mathrm{min}$. Applied potential: 0.70 V vs. Ag/AgCl.

\section{Results and Discussion}

\section{Basic study of detector performance}

To examine the performance of the detector with carbon fiber working electrode in detection of catecholamines, the electrolytic cell was connected with the outlet of the micro separation column using a teflon tube, and the currents at a constant potential of $0.70 \mathrm{~V}$ vs. $\mathrm{Ag} / \mathrm{AgCl}$ were measured on injection of various amounts of catecholamines. Figure 3 shows a typical chromatogram of a standard mixture of NA, AD, DOPA and DA at the flow rate of $4.8 \mu \mathrm{l} / \mathrm{min}$. In this case, each sample amount injected was $100 \mathrm{pg}$. The detection limits were about 1 to $2 \mathrm{pg}(S / N=2)$ for four catecholamines and the linear dynamic range between peak current and sample amount injected was about $10^{3}$ ( $1 \mathrm{pg}-1 \mathrm{ng})$. The relative standard deviations for the determination of catecholamines in each $200 \mathrm{pg}$ were $1.4 \%$ for NA, $2.1 \%$ for AD, $2.3 \%$ for DOPA and $2.5 \%$ for DA, respectively. The electrolytic efficiency of this cell was about $30 \%$ at the flow rate of $4.8 \mu \mathrm{l} / \mathrm{min}$ and decreased to about $10 \%$ at that of $10 \mu \mathrm{l} / \mathrm{min}$ for the DA oxidation.

\section{Application to urinary catecholeamine analysis}

One hundred microliters of human urine were mixed with $100 \mu \mathrm{l}$ of Tris buffer ( $\mathrm{pH} \mathrm{8.6);} \mathrm{the} \mathrm{mixed}$ solution was introduced into an alumina precolumn packed with LiChrosorb Alox $\mathrm{T}$ in a teflon tube $(10 \times 0.25 \mathrm{~mm}$ i.d.) to preconcentrate catecholamines. 


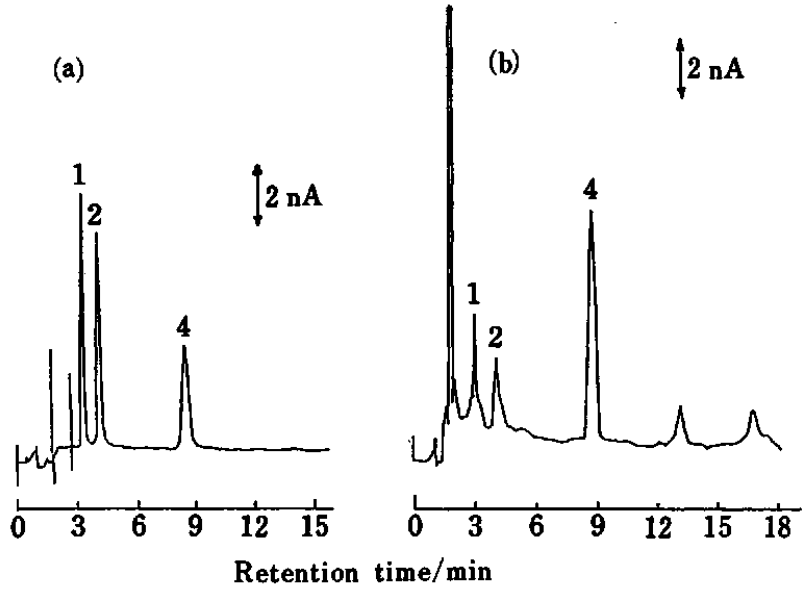

Fig. 4 Application to urinary catecholamine analysis with precolumn method. (a) Standard sample (each $1 \mathrm{ng}$ of catecholamines), (b) urine sample $(100 \mu \mathrm{l})$. Peaks: $\mathrm{l}=\mathrm{NA}$, 2=AD, 4=DA. Mobile phase: methanol-potassium phosphate buffer $(\mathrm{pH} 2.6)=1 / 19$ containing $0.8 \mathrm{mM}$ sodium octylsulfate and $0.2 \mathrm{mM}$ EDTA. Flow rate: $4.2 \mu \mathrm{l} / \mathrm{min}$.

The alumina precolumn was washed with water and then connected with the inlet of micro separation column. The catecholamines adsorbed on alumina were eluted from the precolumn and simultaneously separated by the mobile phase of $\mathrm{pH} 2.6$. The chromatogram of urinary catecholamines is shown in Fig. 4, together with that of standard catecholamines. AD, NA and DA in urine were clearly detected with the proposed cell. DOPA could not be detected in this experimental condition because it might not adsorb on the alumina precolumn. In this method, interference from various metabolites of biogenic amines and uric acid etc. coexistent in urine was successfully removed by purification with alumina precolumn and separation using acidic mobile phase ( $\mathrm{pH} \mathrm{2.6).}$

\section{Application to rapid detection in fast micro $H P L C$}

Speedup of HPLC is very attractive along with the miniaturization of HPLC. Application of the proposed detector to fast micro HPLC of catecholamines and related compounds was tried; the results are shown in Fig. 5 together with those obtained by the UV detector with micro flow cell $(0.05 \mu \mathrm{l})$. In this case, a high pressure pump was required and stainless steel tubes instead of teflon tubes were used from the pump to the micro separation column. It is clear that the proposed electrochemical detector has rapid enough response for fast HPLC, in which the separation time is less than a few minutes. The electrochemical detector with carbon fiber is sensitive not only to catecholamines, but also to their metabolites such as NM and DOPAC, having much higher sensitivity compared with the UV detector in comparable cell volume.

In conclusion, the proposed electrochemical detector using carbon fiber working electrode was proved to be very useful in detection of catecholamines and their

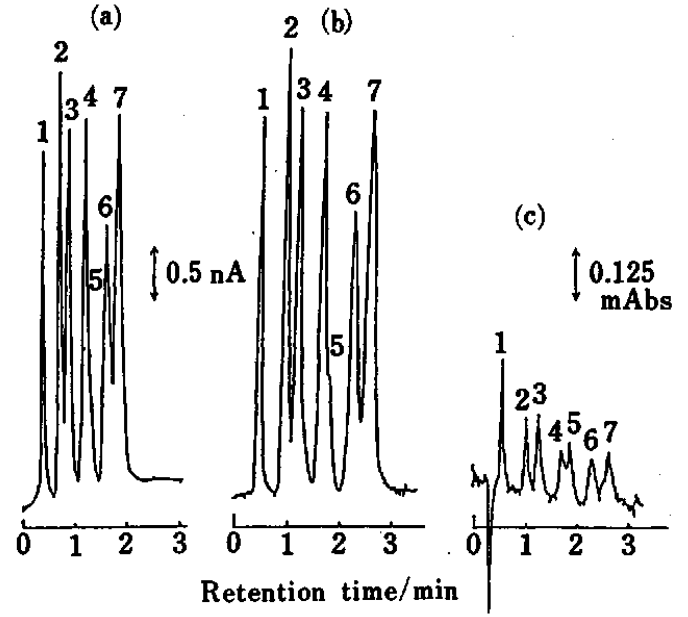

Fig. 5 Application to rapid electrochemical detection in fast micro HPLC, compared with spectrophotometric detection. (a), (b) Electrochemical detections at $700 \mathrm{mV}$ vs. $\mathrm{Ag} / \mathrm{AgCl}$, (c) spectrophotometric detection at $220 \mathrm{~nm}$. Flow rates: (a) $15 \mu \mathrm{l} / \mathrm{min}$, (b), (c) $10 \mu \mathrm{l} / \mathrm{min}$. Mobile phase: methanol-potassium phosphate $(\mathrm{pH} 2.9)=7 / 93$ containing $0.6 \mathrm{mM}$ sodium octylsulfate and $0.2 \mathrm{mM}$ EDTA. Peaks: 1=3,4-dihydroxyphenyl glycol, 2=NA, 3= AD, $4=$ DHBA, $5=$ NM, 6=DOPAC, $7=$ DA. Sample amounts injected: $200 \mathrm{pg}$ each.

metabolites as the detector for micro HPLC. The carbon fiber working electrode has extremely small surface area, leading small charging current and is therefore very suitable for rapid detection and also for rapid scanning voltammetry, compared with the disk electrode ( $3 \mathrm{~mm}$ diameter) used in the conventional electrolytic cell in thin-layer type. Rapid scanning of the working electrode potential adds the potential axis to the current and time axes in the chromatogram and dramatically improves the identification within each chromatographic peak. Application of the proposed detector to rapid scanning electrochemical detection is described elsewhere. ${ }^{17}$

The main part of this work was presented at the seventh international symposium on capillary chromatography held in Gifu on May $11-14,1986$.

\section{References}

1. M. V. Novotny and D. Ishii (eds.), "Microcolumn Separations: Columns, Instrumentation and Ancillary Techniques", Elsevier Scientific Publishers B. V., Amsterdam (1985).

2. Y. Hirata, P. T. Lin, M. Novotny and R. M. Wightman, J. Chromatogr., 181, 287 (1980).

3. M. Goto, Y. Koyanagi and D. Ishii, J. Chromatogr., 208, 261 (1981).

4. M. Goto, T. Nakamura and D. Ishii, J. Chromatogr., 226, 33, (1981).

5. M. Goto, E. Sakurai and D. Ishii, J. Chromatogr., 238, 357 (1982). 
6. M. Goto, Z. Gongwei and D. Ishii, J. Chromatogr., 275, 271 (1983).

7. J. F. Ponchon, R. Cespuglio, F. Gonon, M. Jouvet and J. F. Pujol, Anal. Chem., 51, 1483 (1979).

8. F. G. Gonon, C. M. Fombarlet, M. J. Buda and J. F. Pujol, Anal. Chem., 53, 1386 (1981).

9. R. M. Wightman, Anal. Chem., 53, 1125 A (1981).

10. M. Ikeda, H. Miyazaki, N. Mugitani and A. Matsushita, Nurosci. Res., 1, 171 (1984).

11. M. Goto, in "Quantitative analysis of catecholamines and related compounds", pp. 187-208, ed. A. M. Kistulovic, Ellis Horwood Limited, Chichester, England (1986).

12. K. Aoki, K. Honda, K. Tokuda and H. Matsuda, $J$. Electroanal. Chem. Interfacial Electrochem., 182, 267
(1985).

13. T. Kakutani, H. Miyazaki and M. Ikeda, Bunseki, 1986, 778.

14. L. A. Knecht, E. J. Guthrie and J. W. Jorgenson, Anal. Chem., 56, 479 (1984).

15. R. L. St. Claire III and J. W. Jorgenson, J. Chromatogr. Sci., 23, 186 (1985).

16. J. G. White, R. L. St. Claire III and J. W. Jorgenson, Anal. Chem., 58, 293 (1986).

17. M. Goto and K. Shimada, Chromatographia, 21, 631 (1986).

(Received September 19, 1987)

(Accepted November 14, 1987) 